\title{
A NATUREZA E A ESTRUTURA DAS TEORIAS CIENTÍFICAS*
}

\author{
C. Ulises Moulines ${ }^{\dagger}$ \\ Tradução ${ }^{\ddagger}$ de Cláudio Abreu ${ }^{\S}$
}

\begin{abstract}
In philosophy of science two questions become central in the discussion of the nature of empirical science: 1) What is a (scientific) theory, i.e. how is it built up, how does it work? And: 2) How does a theory relate to its corresponding experiential basis? To deal with these two questions modern philosophy of science has devised various (meta-theoretical) 'models' on the nature and working of scientific theories. Some aspects of these models are widely held within the community of philosophers of science, but others are still being discussed quite controversially. In this paper, we will consider both kinds of aspects. Particularly, we will analyze how the meaning of scientific concepts is determined; the axiomatic construction of a scientific theory; the idea of model building views as a bridge between theory and experience; the holistic semantic thesis of science; the question about the truth of scientific theories and, finally, the hierarchic structure of theories.
\end{abstract}

KEYWORDS: scientific theories - structure - semantics - models

\section{RESUMO}

Na filosofia da ciência duas questões tornam-se centrais na discussão da natureza da ciência empírica: 1) o que é uma teoria (científica)? Ou seja, como é construída, como funciona? E, 2) como é que uma teoria se relaciona com sua base experiencial correspondente? Para lidar com estas duas questões, a moderna filosofia da ciência concebeu vários "modelos" (metateóricos) sobre a natureza e o funcionamento das teorias científicas. Alguns aspectos desses modelos são amplamente aceitos pela comunidade de filósofos da ciência, mas outros ainda estão sendo discutidos de forma bastante controversa. Neste artigo, vamos considerar ambos tipos de aspectos. Particularmente, analisaremos como o significado dos conceitos científicos é determinado; a construção axiomática de uma teoria científica; a ideia de construção de modelos como uma ponte entre a teoria e a experiência; a tese semântica holística da ciência; a questão sobre a verdade das teorias científicas e, finalmente, a estrutura hierárquica das teorias.

PALAVRAS-CHAVE: teorias científicas - estrutura - semântica - modelos

\footnotetext{
* Tradução de: MOULINES, C. U. The Nature and Structure of Scientific Theories. Metatheoria, v. 1, n. 1, p. 15-29, 2010.

† Universidade de Munique.mouline@slrz.uni-muenchen.de.

* Este trabalho foi financiado pelo projeto de investigação PICT-2014-1741 da Agência Nacional de Promoção Científica e Tecnológica da Argentina.

$\S$ Programa de Pós-doutorado, Departamento de Filosofia, Universidade de São Paulo/Centro de Estudios de Filosofía e Historia de la Ciencia, Universidad Nacional de Quilmes. claudioabreu@outlook.com.

Perspectivas - Revista do Programa de Pós-Graduação em Filosofia da UFT - n. 2 - 2018
} 


\section{Introdução}

A ciência empírica é um edifício complexo que consiste em muitos componentes diferentes: instrumentos e métodos de observação, experimentação e computação, aplicações tecnológicas, valores metodológicos e éticos, motivações e pressupostos ideológicos e/ou metafísicos subjacentes e comunidades científicas que estudam uma gama particular de experiências humanas com alguns objetivos particulares em mente. Mas, acima de tudo, a ciência empírica consiste em um tipo particular de entidades abstratas conhecidas como teorias. Instrumentos, métodos, valores, objetivos, comunidades de pesquisa e todo o resto fazem sentido apenas em relação a algumas teorias particulares aceitas e usadas por cientistas. A noção de uma teoria científica é essencial para compreender a natureza da ciência empírica. Portanto, é muito importante para a filosofia da ciência deixar claro que tipo de entidade é uma teoria (científica) e como ela funciona.

No presente artigo, o uso do termo "teoria (científica)" estará restrito às teorias da ciência empírica, ou seja, teorias que, em última análise, direta ou indiretamente, têm algum vínculo com a experiência humana (sensorial). A consideração de teorias puramente lógicas ou matemáticas cai fora do escopo deste artigo, embora alguns dos insights obtidos na filosofia da lógica e da matemática sejam relevantes para algumas questões relativas às teorias empíricas.

$\mathrm{Na}$ atual filosofia da ciência é geralmente aceito que a ideia de uma "experiência absoluta", completamente independente de quaisquer considerações teóricas, é insustentável, pelo menos na ciência. Por esta razão, duas questões tornam-se centrais na discussão da natureza da ciência empírica: 1) o que é uma teoria (científica), ou seja, como é construída, como funciona? e 2) como é que uma teoria se relaciona com a sua base experiencial correspondente? As duas questões estão obviamente inter-relacionadas. Para lidar com estas duas questões, a moderna filosofia da ciência concebeu vários "modelos" (metateóricos) sobre a natureza e o funcionamento das teorias científicas - isto é, concebeu as suas próprias metateorias, por assim dizer, sobre teorias. Alguns desses modelos, ou melhor, alguns aspectos desses modelos, são amplamente difundidos dentro da comunidade de filósofos da ciência, mas outros ainda estão sendo discutidos de forma 
bastante controversa. Vamos começar por considerar o primeiro tipo de aspectos, e depois passar aos mais controversos. ${ }^{1}$

\section{Determinação do significado de conceitos científicos}

O primeiro passo importante na construção de uma teoria científica consiste na indicação de uma série de conceitos específicos, bem como de princípios específicos (leis, ou seja, declarações genéricas). Qualquer teoria científica específica visa a investigação de um domínio particular de nossa experiência, mas o faz assumindo uma estrutura conceitual específica e completamente elaborada, e faz algumas afirmações gerais sobre o domínio considerado; estas afirmações gerais são afirmações formuladas com as noções do quadro conceitual específico. Isto significa que o domínio da experiência a ser investigado tem de ser, em primeiro lugar, interpretado ou reconstruído em termos do quadro conceitual assumido. Como já foi salientado, a ideia de uma experiência pré-conceitual é insustentável num contexto científico. Considere, por exemplo, o domínio da experiência relevante para a ciência da mecânica: este domínio é interpretado ou concebido em termos de noções como partícula, posição, tempo, velocidade, massa etc. Por outro lado, se quisermos lidar com o domínio correspondente aos objetivos da teoria da decisão, usaremos noções como ação, incerteza, utilidade esperada, probabilidade subjetiva e similares.

É importante notar a especificidade e precisão dos conceitos relevantes para a construção de uma teoria científica adequada. São de natureza bastante diferente das noções habituais que empregamos na vida quotidiana. É verdade que os conceitos científicos são frequentemente expressos por meio de palavras provenientes da linguagem cotidiana (uma característica que geralmente sugere as origens históricas da disciplina em questão); no entanto, essas expressões normalmente têm um uso altamente transformado e, acima de tudo, mais preciso, quando comparado com a linguagem cotidiana. $\mathrm{O}$ uso das palavras portuguesas "força” ou "campo" em um livro de física é remotamente (se é que é) relacionado ao seu uso no português cotidiano. Além disso, em muitas teorias científicas,

\footnotetext{
${ }^{1}$ Dois relatos clássicos das duas questões centrais acima mencionadas, e em particular a questão da relação entre teoria e experiência, encontram-se em Nagel (1961) e em Stegmüller (1970). Uma abordagem diferente e mais recente a estas questões é oferecida pela chamada visão semântica das teorias - ver, por exemplo, van Fraassen (1980) e Suppe (1989). A chamada visão estruturalista das teorias oferece o relato mais complexo até agora da estrutura das teorias e suas relações com o "mundo exterior". A exposição padrão desta visão é Balzer, Moulines e Sneed (1987). Díez e Moulines (1999) contém uma exposição detalhada dessas diferentes concepções. Uma comparação das diferentes visões filosóficas sobre teorias a partir de uma perspectiva histórica é oferecida em Moulines (2006).
}

Perspectivas - Revista do Programa de Pós-Graduação em Filosofia da UFT - n.2 - 2018 
encontramos termos que são neologismos completos (pense em "entropia", "spin", "gene"...) e que ou não têm uso na linguagem cotidiana, ou então, se agora têm tal uso, foi importado da ciência ("gene" seria um bom exemplo disso). A justificativa para a introdução de tais termos não é o desejo de desorientar o leigo e inventar uma linguagem enigmática conhecida apenas por uma panelinha, mas sim evitar falsas associações e expectativas, e ser o mais preciso possível.

Agora, se o significado dos termos científicos geralmente não coincide com o significado das expressões cotidianas, surge imediatamente a questão: como eles obtêm seu próprio significado? Não se trata de uma questão trivial, mas sim de um problema central na filosofia da ciência. A resposta a essa pergunta é tudo menos simples. As diferentes abordagens que foram oferecidas para respondê-la pertencem, pelo menos em parte, a alguns dos pontos mais controversos da moderna filosofia da ciência. Voltaremos a esta questão mais adiante. Por enquanto, vamos apenas fazer a seguinte observação. Os conceitos científicos nunca obtêm seu significado próprio um por um - não existe um conceito científico 'isolado'; eles obtêm seu significado no contexto de toda uma série de outros conceitos bem determinados; juntos, eles constroem uma estrutura conceitual específica.

Diz-se muitas vezes que a forma padrão de determinar o significado de conceitos científicos é, exceto no caso das noções quotidianas, defini-las rigorosamente. Isso só é parcialmente verdadeiro, e isto por duas razões. Primeiro, definir um termo $A$ significa colocá-lo em uma relação sistemática com outros termos, digamos, $B, C, D \ldots$ Ora, se esta vai ser uma definição real, é preciso garantir que o conteúdo da informação fornecida por $A$ seja exatamente o mesmo que o fornecido pela combinação de $B, C, D \ldots$ Isso significa que $A$ e a combinação de $B, C, D \ldots$ têm de ser semanticamente equivalente. ${ }^{2}$ (Por exemplo, a noção de velocidade média na mecânica pode ser definida por meio dos conceitos de "distância" e "intervalo de tempo" porque a primeira noção é semanticamente equivalente a "distância percorrida dividida pelo intervalo de tempo decorrido".) No entanto, nem todas as conexões conceituais que aparecem em um contexto científico podem ser interpretadas como tais equivalências semânticas. Em muitos casos, o que temos são apenas conexões mais ou menos parciais que não correspondem a uma coincidência conceitual completa. (Pense em "definir" a energia de um gás, na termodinâmica, como a

\footnotetext{
${ }^{2}$ Um tratamento preciso da teoria da definição pode ser encontrado em Suppes (1957).

Perspectivas - Revista do Programa de Pós-Graduação em Filosofia da UFT - n.2 - 2018
} 
derivada parcial da pressão em relação ao volume: isso só pode ser aceito se outros parâmetros relevantes forem supostamente mantidos constantes.)

A segunda razão pela qual as definições não podem ser a regra geral para determinar o significado de conceitos científicos é mais fundamental. É logicamente impossível definir todas as noções relevantes de uma determinada disciplina científica: isso levaria ou a uma infinita cadeia de definições (uma ideia absurda), ou então a um círculo vicioso. (Suponha, para simplificar, que nossa disciplina conteria apenas três conceitos, $A, B$ e $C$; deveríamos primeiro definir $A$ em termos de $B$ e $C$; mas então deveríamos definir $B$ em termos de $A$ e $C$, portanto não definindo nada; o argumento é aplicável a qualquer conjunto finito de conceitos).

A consequência deste fato lógico é que, em qualquer teoria, temos que admitir um certo número de conceitos como indefinidos. Na terminologia usual na filosofia formal da ciência, tais noções são chamadas "conceitos primitivos" ou também "conceitos básicos". Uma vez que tenhamos admitido um desses conjuntos de conceitos básicos, temos de ter cuidado para que as demais noções específicas da teoria possam ser introduzidas como conceitos definidos por meio de cadeias de definição rigorosamente construídas, sendo todos os seus membros equivalências semânticas. Desde os tempos pioneiros da filosofia formal da ciência há um amplo consenso sobre as regras que as cadeias de definição devem cumprir para obter definições genuínas. ${ }^{3}$ De qualquer forma, é bastante claro como os conceitos definidos adquirem seu significado em uma teoria: através de cadeias de definição que eventualmente levam ao significado dos conceitos básicos. Mas nessas circunstâncias ainda somos confrontados com a questão fundamental de como os conceitos básicos adquirem seu significado determinado.

\section{A construção axiomática de uma teoria científica}

Para lidar com a última questão, temos de aprofundar a nossa análise da estrutura das teorias científicas. Já foi apontado que os conceitos científicos não aparecem isolados, mas sim em "clusters". Este facto é particularmente significativo para o problema da determinação do significado dos conceitos básicos de uma determinada teoria. Tipicamente, tais conceitos não aparecem isolados em afirmações simples; ao contrário, eles aparecem interconectados nos princípios gerais e fundamentais da teoria, isto é, em

\footnotetext{
${ }^{3}$ Não podemos entrar aqui na explicação destas regras. Sua exposição abrangente pode ser encontrada em Suppes (1957).

Perspectivas - Revista do Programa de Pós-Graduação em Filosofia da UFT - n.2 - 2018
} 
seus axiomas. Certamente, uma teoria consiste, em um primeiro momento, em uma estrutura conceitual específica; mas é uma estrutura dentro da qual algumas afirmações de fato sobre o mundo devem ser feitas; e quando essas afirmações são justificadas, obtemos algum conhecimento sobre o mundo. Não obstante, as afirmações mais importantes que uma teoria faz são precisamente aquelas que são essenciais para obter as peças de conhecimento que pretendemos. Estes são os axiomas da teoria. Eles consistem em conexões básicas entre conceitos básicos. Pelo menos em princípio, todas as outras afirmações de fato que queremos fazer sobre o mundo na teoria têm que ser derivadas dos axiomas como teoremas.

Consequentemente, definições, axiomas e teoremas são as três categorias fundamentais de afirmações que constroem uma teoria científica. Sempre que uma teoria é construída de forma tão rigorosa que podemos determinar claramente quais afirmações são definições genuínas, quais são axiomas e quais são teoremas, e quando todos os membros da última categoria podem logicamente ser deduzidos dos axiomas (e possivelmente das definições), então dizemos que a teoria foi axiomatizada. Deve-se observar, entretanto, que a axiomatização de uma teoria muito frequentemente representa um ideal (um princípio regulador) e não tanto uma realidade dentro da prática científica. (Somente dentro das disciplinas formais da lógica e da matemática pode-se dizer que quase todas as teorias existentes foram rigorosamente axiomatizadas). Nas ciências empíricas, a construção axiomática de uma teoria é mais a exceção do que a regra. Apenas algumas teorias empíricas, que são consideradas particularmente fundamentais, foram axiomatizadas mais ou menos completamente; podemos mencionar os exemplos da mecânica newtoniana, termodinâmica, mecânica quântica e genética clássica. Esta situação deve-se em parte a contingências históricas (a tradição de axiomatização é muito mais forte na matemática do que na ciência empírica desde a Antiguidade), em parte devido a razões sistemáticas (normalmente as teorias empíricas são estruturalmente muito mais complexas do que as teorias matemáticas). Seja como for, de um ponto de vista epistemológico, a correta axiomatização das teorias empíricas ainda é um ideal genuíno porque é somente com este procedimento que podemos abordar frutuosamente a questão do significado e da função dos conceitos e afirmações científicas. A propósito, isto explica o fato de que nas últimas 
décadas foram sobretudo os filósofos da ciência, e não tanto os próprios cientistas praticantes, que empreenderam a tarefa de axiomatizar teorias empíricas importantes. ${ }^{4}$

\section{A construção de modelos como ponte entre teoria e experiência}

Sempre que uma teoria tenha sido completamente axiomatizada, sabemos exatamente quais conceitos, entre suas noções específicas, pertencem ao conjunto de noções definidas e quais pertencem ao conjunto de conceitos básicos ou primitivos. Já vimos que o significado dos conceitos definidos se reduz ao significado de algumas combinações dos conceitos definidores, o que significa, em última análise, combinações dos conceitos básicos. O significado dos conceitos básicos, por sua vez, é então parcialmente determinado pelas conexões entre eles que são expressas nos axiomas. Poderíamos também dizer: os axiomas ou princípios postulados fornecem por si mesmos o significado dos conceitos básicos. Mas isto é só parcialmente verdadeiro. Se o significado dos conceitos básicos de qualquer teoria fosse determinado exclusivamente por seus axiomas, então não haveria diferença de princípio entre uma teoria empírica e uma teoria puramente matemática, uma vez que é precisamente uma característica distintiva das teorias matemáticas que seu próprio quadro conceitual seja estabelecido apenas 'internamente' (axiomaticamente). Por outro lado, a estrutura conceitual de uma teoria empírica não foi concebida para flutuar livremente no céu das ideias abstratas. O objetivo de uma teoria genuinamente empírica é estar ancorada no mundo da experiência, e é essa ancoragem que também dá seu significado aos conceitos básicos. A estrutura conceitual (e, portanto, as afirmações que fazemos dentro dela) tem de ser interpretada na realidade empírica. Como podemos atingir esse objetivo?

Embora ainda não exista uma abordagem uniformemente aceite na filosofia contemporânea da ciência em relação a esta questão, existe atualmente um amplo consenso sobre o significado da noção de um modelo para lidar com a questão em causa. O conceito de modelo a que aqui nos referimos remonta a desenvolvimentos na semântica formal,

\footnotetext{
${ }^{4}$ Vários exemplos de axiomatizações rigorosas de teorias empíricas no âmbito da filosofia "clássica" da ciência podem ser encontrados em Kyburg (1968). Ver também a antologia editada por Henkin, Suppes e Tarski (1959). Para exemplos de axiomatizações dentro de uma estrutura metateórica diferente, "não clássica", ver Balzer, Moulines e Sneed (1987). Neste trabalho, a chamada metodologia "estruturalista" de axiomatização é aplicada a vários exemplos de teorias da física e da química. Mais exemplos de axiomatizações segundo estas linhas de teorias de diferentes disciplinas, incluindo as ciências sociais, podem ser encontrados em Balzer, Moulines e Sneed (2000).

Perspectivas - Revista do Programa de Pós-Graduação em Filosofia da UFT - n.2 - 2018
} 
especialmente na obra de Alfred Tarski. ${ }^{5}$ Afirmar que o quadro conceitual de uma teoria pode ser interpretado num determinado domínio da experiência equivale a afirmar que esse domínio (ainda que de forma simplificada ou idealizada) pode ser concebido como um modelo dos axiomas da teoria. É desta forma que os conceitos que aparecem nos axiomas obtêm seu conteúdo empírico. Num modo de falar diferente, embora essencialmente equivalente, podemos dizer que a teoria (ou seja, o seu quadro conceitual e as afirmações nele contidas) representa o domínio em questão por meio da construção de um modelo. Outra forma de dizer isto é que um modelo é uma estrutura construída por meio dos conceitos da teoria que abrange o domínio experiencial que pretendemos estudar (de forma mais ou menos idealizada).

Em vez de fornecer uma explicação geral e abstrata da noção de modelo e do procedimento associado aos modelos de construção, vamos expor os aspectos essenciais desta concepção através de um exemplo simples e esquemático. Suponhamos que um grupo de cientistas (uma "comunidade científica") esteja interessado na investigação teórica de um determinado domínio de experiência, digamos, uma série de pontos de luz sobre o céu noturno que se movem lentamente e tomam diferentes posições sobre o céu todas as noites ao mesmo tempo. O primeiro passo a ser dado pelo grupo de pesquisadores é codificar as observações imediatas que fazem sobre os pontos de luz com os olhos nus ou com a ajuda de dispositivos particulares como telescópios em uma chamada estrutura de dados, geralmente chamada também de "modelo de dados". Esta "codificação" implica que as observações feitas serão idealizadas drasticamente (isto é, seus aspectos mais complexos serão simplesmente postos de lado) e interpretadas de uma certa forma. Por exemplo, os pontos de luz serão concebidos como esferas perfeitas que estão em uma posição precisa no espaço em qualquer instante de tempo em particular. Por enquanto, isto é tudo o que parece ser interessante em relação aos pontos de luz - e não, digamos, que cor eles têm ou se parecem maiores ou menores que outros pontos de luz. Os corpos esféricos junto com a indicação de suas posições e tempos constituem os "dados" observados. Sua montagem coerente e sistemática constitui o modelo de dados que os cientistas estão interessados em explicar. ${ }^{6}$ Numa segunda etapa, o modelo de dados será extrapolado para curvas contínuas de uma forma particular, por exemplo, elipses. Note-se já neste ponto a

\footnotetext{
${ }^{5}$ Veja Tarski (1956). Uma aplicação da noção de modelo de Tarski às teorias empíricas pode ser encontrada em Suppes (1957).

"A noção de "modelo de dados" ["data model"] ou "modelos de dados" ["models of data"] remonta a Suppes (1962).

Perspectivas - Revista do Programa de Pós-Graduação em Filosofia da UFT - n.2 - 2018
} 
natureza fortemente hipotética do procedimento do nosso grupo de pesquisadores: eles 'apostam' que a suposição de que os pontos de luz interessantes são como esferas perfeitas movendo-se sobre elipses é uma abordagem promissora para uma interpretação teórica apropriada do domínio da experiência em jogo. Mas, é claro, eles não têm nenhuma prova formal de que isso deve ser assim. O próximo passo é ainda mais ousado. Consiste em atribuir aos pontos de luz observados um certo conjunto de "parâmetros"; eles são, na maioria das vezes, magnitudes, ou seja, atribuições de números a objetos empíricos. São supostos para ajudar a explicar os movimentos das coisas observadas. No nosso exemplo, tais magnitudes poderiam ser, digamos, velocidade, aceleração, massa e força; ou são conceitos definidos ou básicos que aparecem numa determinada teoria (digamos mecânica newtoniana). Além disso, supor-se-á que essas grandezas têm sempre valores precisos nas observações já feitas ou nas que ainda não foram feitas. (Não podemos entrar aqui no tema da determinação de tais valores; esta é uma questão que pertence a um dos capítulos mais complexos da filosofia da ciência - os fundamentos da medição). ${ }^{7}$ Depois de feitos todos estes passos, os corpos esféricos com as indicações das suas posições e tempos, bem como as outras grandezas mencionadas, constituem uma estrutura matemática (que, por mais matemática que seja, acaba por radicar nos dados empíricos). Desta estrutura, os pesquisadores afirmam agora que ela satisfaz (pelo menos aproximadamente) os princípios (axiomas) de uma teoria particular, a mecânica newtoniana; em outras palavras, eles afirmam que é um modelo de mecânica newtoniana. Se esta afirmação for verdadeira (isto é, se nenhuma inconsistência aparecer dentro de uma margem de erro aceitável, previamente determinada, entre as observações e medições feitas por um lado e as esperadas de acordo com as leis de Newton, por outro), então podemos dizer que o modelo de dados originalmente construído pelo grupo de pesquisa a partir de suas observações dos pontos de luz, é “coberto" ou "representado" por um modelo de mecânica newtoniana.

O exemplo anterior, que é reconhecidamente bastante esquemático e fortemente simplificado, já permite tomar nota da complexidade e dos diferentes níveis do processo de construção de modelos; este é o processo que conecta uma determinada teoria com o domínio da experiência a que se destina. Dentro de um contexto científico, nunca há uma espécie de "encontro direto" entre teoria e experiência.

\footnotetext{
${ }^{7} \mathrm{O}$ trabalho de referência padrão nesta área é Krantz et al. (1971). Uma exposição histórica do assunto pode ser encontrada em Díez (1997a) e Díez (1997b). Para mais desenvolvimentos, ver Moulines e Díez (1994). Perspectivas - Revista do Programa de Pós-Graduação em Filosofia da UFT - n.2 - 2018
} 


\section{A semântica holística da ciência}

Voltemos agora ao problema semântico que o nosso simples exemplo pretendeu ilustrar: como é que os conceitos básicos da mecânica newtoniana (partícula, posição, tempo, massa, força) adquirem o seu próprio significado? A resposta é bidimensional. Por um lado, como já vimos antes, seu significado é parcialmente determinado pela forma como estão "unidos" dentro de alguns princípios gerais, por exemplo, os axiomas newtonianos. Mas em uma teoria empírica como a mecânica, esta é apenas uma das dimensões da determinação do conteúdo conceitual. A outra dimensão consiste no fato de que esses conceitos básicos se ligam, ainda que indiretamente, aos pontos de luz móveis no céu (nossa experiência "imediata") através do processo complexo e multinível de construção de modelos que acabamos de descrever. A primeira dimensão da determinação do significado pode ser caracterizada como "formal-axiomática" (e, neste sentido, é completamente análoga à determinação do significado de conceitos básicos em teorias puramente matemáticas); a segunda dimensão, por outro lado, pode ser descrita como "empírica/orientada para aplicação" (e é precisamente uma característica distintiva das teorias empíricas). É de notar que este segundo aspecto da interpretação de conceitos científicos pode ser visualizado como uma espécie de "via de dois sentidos": por um lado, os elementos do processo de construção de modelos são interpretados através do tipo de experiência original que supostamente devem cobrir; por exemplo, pode-se argumentar que ninguém compreende completamente o que "força", "massa", etc. realmente significam, a menos que saiba que estas noções podem ser usadas para a apreensão conceitual de, entre outras coisas, certos pontos de luz sobre o céu noturno. Mas temos que levar em conta também a outra direção da 'estrada de interpretação': o sucesso na aplicação do modelo da teoria nos permite afirmar que as observações feitas originalmente no céu noturno se referem a "partículas que, a qualquer tempo, têm uma posição particular no espaço e uma massa, e estão sujeitas a algumas forças particulares". Ou seja, os pontos de luz originais são reinterpretados como partículas com todas essas propriedades e magnitudes.

Devido à complexidade do processo de interpretação dos conceitos científicos, muitos filósofos contemporâneos da ciência têm argumentado que a semântica dos conceitos científicos (ou seja, a estrutura de sua determinação de significado) tem um caráter holístico. Isto significa que é sempre uma totalidade conceitual não decomponível 
que é objeto de uma determinação de sentido. A explicação precisa da estrutura de tais conjuntos semânticos é uma tarefa primordial para a moderna filosofia da ciência. ${ }^{8}$

O grau de complexidade da totalidade semântica característica da ciência teórica pode tornar-se ainda maior por causa da seguinte característica das teorias empíricas. Em todas essas teorias que estão um pouco bem desenvolvidas, notamos que seus respectivos quadros conceituais não são usados apenas para apreender conceitualmente apenas um domínio da experiência. Muito pelo contrário, a mesma estrutura conceitual pode ser aplicada a domínios muito diferentes. Voltando ao nosso exemplo: os conceitos de "partícula", "força", "massa", etc., bem como as suas ligações mútuas expressas nos axiomas newtonianos, são usados não só para interpretar as observações sobre o céu noturno, mas também para cobrir domínios bastante diferentes, como experiências com pêndulos, corpos em queda livre, osciladores, colisões de bolas de bilhar e muitas outras coisas. Nesse sentido, os filósofos da ciência costumam dizer que os modelos de teorias bem desenvolvidas e seus conceitos constituintes são "semanticamente multivocais".

\section{As teorias científicas são verdadeiras?}

Até aqui, tratamos apenas de um grande tema da filosofia moderna da ciência: a semântica do marco conceitual de uma teoria. Há, no entanto, outro tema que é pelo menos igualmente central para a análise filosófica da ciência: o problema do teor de verdade das teorias empíricas. As teorias são construídas não apenas com o objetivo de conceituar uma determinada gama de fenômenos, mas também com o propósito de explicar, prever, controlar e talvez até mesmo manipular fenômenos, e de fazer isso com sucesso. Por exemplo, o quadro conceitual da mecânica newtoniana foi criado não só para sistematizar e interpretar conceitualmente as observações feitas em vários domínios da experiência, mas também para explicar os movimentos dos corpos, predizer as suas posições futuras e construir alguns dispositivos e máquinas úteis, ou para facilitar a navegação. As explicações, previsões, manipulações de fenômenos feitos com base em uma determinada teoria têm que se encaixar e, quando este é o caso, intuitivamente, gostaríamos de afirmar que a teoria é verdadeira.

\footnotetext{
${ }^{8}$ O precursor do holismo na filosofia da ciência é Duhem ([1906] 2001). Uma versão mais radical do holismo na ciência é representada por W. V. O. Quine, por exemplo, em (1953). Uma versão mais sofisticada do holismo pode ser encontrada em Stegmüller (1973) e em Balzer, Moulines e Sneed (1987). Perspectivas - Revista do Programa de Pós-Graduação em Filosofia da UFT - n.2 - 2018
} 
Duas questões surgem ao tentar explicar essa expectativa intuitiva sobre teorias em termos mais precisos. As duas questões estão inter-relacionadas, mas é conveniente formulá-las em termos separados. A primeira questão com a qual temos que lidar é se uma teoria é realmente o tipo de entidade da qual devemos querer predicar a verdade; talvez devêssemos estar satisfeitos (pelo menos no caso das teorias empíricas) com um tipo de afirmação um pouco mais fraco, como afirmar que a teoria em questão parece ser útil, frutífera ou empiricamente adequada, ou algo do tipo. Os filósofos da ciência tendem a aplicar o predicado "verdadeiro" (ou o seu oposto "falso") às teorias, ${ }^{9}$ enquanto os nãorealistas tendem a usar o tipo mais fraco de predicado que acabamos de mencionar. ${ }^{10}$

Vamos assumir, por enquanto, que faz sentido predicar a verdade (ou falsidade) das teorias. (Vamos considerar a alternativa 'mais fraca' ais adiante.) A segunda questão é então descobrir as condições lógicas e metodológicas que devem ser satisfeitas a fím de serem justificadas na reivindicação da verdade de uma teoria.

Nos tempos pioneiros da moderna filosofia da ciência, supunha-se naturalmente que bastaria ter um número suficientemente grande de dados observacionais que concordassem com as afirmações da teoria para garantir que a teoria fosse realmente verdadeira. Essa é essencialmente a visão clássica do indutivismo: a verdade, ou pelo menos a "verdade provável", de uma teoria é garantida por um número suficientemente grande (mas finito) de suas instâncias positivas. Ao contrário do caso da matemática pura, a indução parece ser a metodologia típica da ciência empírica. (Por essa razão, as disciplinas empíricas eram frequentemente caracterizadas como "ciências indutivas" - por contraposição à lógica e à matemática como "ciências dedutivas".) No século XX, essa visão foi proeminentemente apresentada por Rudolf Carnap. Ele até desenvolveu um "sistema de lógica indutiva" bastante sofisticado, com o objetivo de estabelecer as regras formais destinadas a assegurar a verdade, ou provável verdade, de uma teoria a partir de um conjunto finito de instâncias de aplicação. ${ }^{11}$

Em oposta e explícita oposição a Carnap, outro influente filósofo da ciência do século XX, Karl Popper, propôs a metodologia do falseacionismo. ${ }^{12}$ Segundo ele, os

\footnotetext{
${ }^{9}$ Para uma defesa clássica deste ponto de vista, ver Popper (1958), que é a edição inglesa revista e ampliada do Popper original alemão (1934); ver também Popper (1972).

${ }^{10}$ Uma interpretação decididamente antirrealista das teorias pode ser encontrada em van Fraassen (1980). Para uma visão mais qualificada sobre esta questão, ver Balzer, Moulines e Sneed (1987).

11 A exposição clássica de Carnap de sua lógica indutiva pode ser encontrada em Carnap (1952); desenvolvimentos adicionais estão incluídos em Carnap e Jeffrey (1971).

12 Pela primeira vez em Popper (1934).

Perspectivas - Revista do Programa de Pós-Graduação em Filosofia da UFT - n.2 - 2018
} 
cientistas certamente devem tentar desenvolver verdadeiras teorias; mas eles nunca serão capazes de garantir que suas teorias sejam realmente verdadeiras, nem mesmo provavelmente verdadeiras. Mesmo muitas instâncias positivas na aplicação de uma teoria não garante a afirmação de sua verdade e nem mesmo de sua probabilidade. A razão é que uma teoria genuinamente científica (além de um mero registro de dados) sempre é, em princípio, mais geral do que os dados observacionais que ela abrange em um dado momento; portanto, nunca se pode excluir que uma observação realizada implique que a teoria assumida é falsa afinal. $\mathrm{O}$ que os cientistas podem fazer não é provar que uma determinada teoria é verdadeira, mas apenas que é falsa: mesmo que tenhamos muitos dados positivos, basta ter um único caso negativo para declarar a teoria como falsa. A razão disso, por sua vez, é um princípio puramente lógico: a regra conhecida como modus tollens. Vamos explicá-la por meio de um exemplo simples: suponha que tenhamos exposto a 'teoria' de que todos os corvos são negros e suponha que tenhamos observado milhares de corvos negros; basta observar um dia um corvo de cor diferente para rejeitar a teoria como falsa. Com base nessas considerações, Popper propôs o falseacionismo como o único método genuíno de pesquisa nas disciplinas empíricas.

Poucos filósofos da ciência hoje aceitariam o indutivismo de Carnap ou o falseacionismo de Popper em suas versões originais. Ambos encontram problemas muito sérios. As dificuldades do indutivismo são principalmente de natureza lógico-formal: os sistemas de lógica indutiva criados por Carnap e seus seguidores provaram ser formalmente inconsistentes ou não aplicáveis a teorias realmente existentes. ${ }^{13}$ As dificuldades do falseacionismo são mais do que um caráter metodológico: a 'multivocalidade' semântica dos conceitos básicos em diferentes modelos de uma e mesma teoria, assim como a natureza idealizadora e aproximativa dos axiomas tornam qualquer teoria científica bem desenvolvida suficientemente flexível para assumir a presença de “fatores perturbadores' que podem explicar as instâncias de aplicação negativa de uma teoria sem abrir mão da própria teoria. ${ }^{14}$ No entanto, tanto o indutivismo quanto o falseacionismo contêm um 'grão de verdade' - o primeiro destacando a importância do raciocínio probabilístico na aplicação de teorias empíricas, o segundo enfatizando o caráter

\footnotetext{
${ }^{13}$ Para uma extensa análise e crítica da lógica indutiva de Carnap, ver Stegmüller (1974).

${ }^{14} \mathrm{O}$ crítico mais proeminente do falseacionismo de Popper do ponto de vista histórico é Thomas S. Kuhn em seu Kuhn (1962). Veja também, de uma perspectiva mais formal, Stegmüller (1973).

Perspectivas - Revista do Programa de Pós-Graduação em Filosofia da UFT - n.2 - 2018
} 
completamente hipotético dos princípios básicos de uma teoria e a necessidade de uma séria consideração daqueles casos em que uma teoria se desvia.

No entanto, as deficiências realmente fundamentais das abordagens clássicas da filosofia da ciência, como as de Carnap, Popper e seus seguidores, estão em um nível mais profundo: vêm de sua visão demasiado simplista da estrutura interna de uma teoria científica. Estas abordagens veem a identidade de uma determinada teoria simplesmente dada por um conjunto de axiomas e suas consequências lógicas. Com uma tal compreensão da natureza de uma teoria científica, segue-se obviamente que uma teoria só pode ser verdadeira (se todos os seus axiomas forem verdadeiros) ou falsa (se os axiomas conduzirem a consequências falsas). Neste tipo de abordagens, a noção de um modelo, que vimos ser tão importante para compreender a forma como as teorias se relacionam com a experiência, não desempenha qualquer papel essencial; isto explica, pelo menos em parte, a simplicidade de espírito das abordagens clássicas da filosofia da ciência e suas deficiências ao lidar com a questão da relação entre teoria e experiência. Se, por outro lado, colocarmos a noção de modelo no foco das considerações metateóricas - como a maioria das abordagens contemporâneas na filosofia da ciência,$-{ }^{15}$ então chegaremos a uma visão mais sofisticada, mais flexível e mais adequada da estrutura das teorias científicas e da forma como são aplicadas. Concebendo teorias não tanto como um conjunto de axiomas, definições e teoremas, mas sim como uma classe de modelos estruturalmente semelhantes entre si, mas diferentes na sua interpretação empírica, e tendo em conta a complexidade do processo que liga um "modelo de dados" ao seu correspondente modelo completo, obtemos a seguinte visão, mais equilibrada e flexível, da estrutura e funcionamento das teorias. ${ }^{16}$ Qualquer teoria científica bem desenvolvida consiste em um conjunto aberto de modelos, todos eles formalmente determinados pelas mesmas fórmulas tomadas como axiomas, mas recebendo diferentes interpretações de acordo com o modelo de dados que cada modelo pretende cobrir. Pode então acontecer (e é precisamente o que acontece no caso normal) que uma única teoria consista em alguns modelos que representam (no sentido acima explicado) muito bem os seus modelos de dados, em outros modelos que os representam menos bem e, finalmente, em alguns modelos que se encaixam muito mal, ou não se encaixam. Sob esta concepção, a aceitação ou rejeição de uma teoria não pode ser vista como uma questão de 'tudo ou nada'. Tudo o que podemos dizer é que existem

${ }^{15}$ Ver, por exemplo, van Fraassen (1980), Suppe (1989) ou Balzer, Moulines e Sneed (1987).

${ }^{16}$ Para uma exposição detalhada desta visão sobre teorias, ver Balzer, Moulines e Sneed (1987). Perspectivas - Revista do Programa de Pós-Graduação em Filosofia da UFT - n.2 - 2018 
teorias que funcionam melhor do que outras no sentido de que cobrem mais modelos de dados e os cobrem melhor do que as suas rivais. Naturalmente, se uma teoria é tal que nenhum dos seus modelos cobre nenhum dos modelos de dados para os quais os primeiros foram concebidos, então podemos seguramente rejeitar a teoria completamente. Mas este não é um caso que normalmente aconteça em qualquer disciplina científica que satisfaça alguns padrões metodológicos mínimos de rigor e honestidade intelectual. Por outro lado, provavelmente não houve na história da ciência uma teoria tal que todos os seus modelos funcionem perfeitamente.

Assumindo esta ideia de teorias centradas em torno do conceito de modelo, torna-se claro agora porque é difícil manter uma visão realista e intransigente das teorias científicas no que diz respeito à sua verdade ou falsidade. Estritamente falando, não podemos mais dizer que uma dada teoria é verdadeira ou falsa, ponto final. Pelo contrário, devemos dizer que uma teoria é "perfeitamente verdadeira" em alguns modelos, "menos verdadeira" em outros modelos, e "não verdadeira" em outros modelos ainda. Mas, de um ponto de vista rigorosamente formal, esta não é uma maneira muito sensata de falar. Seria melhor apenas dizer que uma teoria é perfeitamente adequada (ou "se aplica perfeitamente bem") em alguns modelos, é menos adequada (ou "se aplica apenas até certo ponto") em alguns outros modelos, e é completamente inadequada (ou "não se aplica") em outros modelos ainda. Em suma, a avaliação metodológica das teorias científicas surge como uma questão gradual.

\section{A estrutura hierárquica das teorias científicas}

Vimos que conceber uma teoria como uma pluralidade de modelos fornece uma análise mais perspicaz da sua 'essência' do que concebê-la apenas como um conjunto de afirmações. Agora, é importante ter consciência de que esta pluralidade é multifacetada em dois aspectos. Um deles já foi salientado: embora todos os modelos que constituem uma teoria satisfaçam os mesmos axiomas (como fórmulas), seu conteúdo pode variar de acordo com as diferentes interpretações empíricas que damos a essas fórmulas e os termos básicos que ocorrem nelas - diferenças que, por sua vez, são provocadas pelos diferentes modelos de dados que queremos cobrir em nossa teoria. Mas há outro sentido importante no qual a pluralidade de modelos de uma teoria é multifacetada: os vários modelos de uma teoria podem parecer ter diferentes graus de generalidade. Alguns modelos são mais gerais 
ou 'mais abstratos' do que outros; ou, dito de outra forma, alguns modelos estão 'mais próximos' de seus modelos de dados correspondentes do que outros. Isto vem, por sua vez, do fato de que nem todos os axiomas que determinam os modelos têm o mesmo status metodológico e epistemológico. Alguns estão 'mais próximos' da base experiencial do que outros. Parafraseando a famosa frase de George Orwell, poderíamos também dizer que, embora todos os axiomas sejam axiomáticos, alguns axiomas são 'mais axiomáticos' que outros. Considere novamente o exemplo da mecânica newtoniana. Os modelos determinados pelos três princípios básicos de Newton são extremamente gerais. Eles são mais gerais, de qualquer forma, do que aqueles que, além disso, têm que satisfazer a lei da gravitação. Estes, por sua vez, são mais gerais do que aqueles que também têm de satisfazer as equações de algumas forças de atrito, ou qualquer outra coisa. Há também tipos de modelos que não podem ser comparados quanto ao fato de serem mais ou menos gerais do que outros tipos. Por exemplo, os modelos newtonianos que satisfazem equações de forças de atrito não são mais nem menos gerais do que os modelos newtonianos que satisfazem as leis da eletrostática de Coulomb. ${ }^{17}$ Isto significa, a propósito, que seria completamente inadequado dizer que consideramos como modelos de mecânica newtoniana apenas aquelas estruturas que satisfazem todas as leis particulares que aparecem em um livro sobre mecânica newtoniana. Se considerássemos apenas os modelos que satisfazem todas as leis mecânicas, acabaríamos por ter uma teoria desprovida de conteúdo empírico, pois muito provavelmente não existe um único modelo de dados que esteja coberto por todas as leis mecânicas. Para lidar com alguns modelos de dados só precisamos, digamos, dos princípios fundamentais de Newton; para lidar com outros, precisamos também da lei da gravitação; para lidar com outros ainda, precisamos das leis de Coulomb, além dos princípios fundamentais, e assim por diante.

A imagem que surge dessas considerações é a de uma matriz hierarquicamente construída de axiomas e seus tipos correspondentes de modelos. Alguns axiomas são extremamente gerais e devem ser cumpridos em todos os modelos da teoria em questão; alguns outros ainda são bastante gerais, mas não devem ser cumpridos em todos os casos; alguns outros, finalmente, são muito particulares e destinam-se a lidar apenas com aplicações muito concretas, como as que interessam aos engenheiros. Portanto, qualquer teoria empírica que tenha sido desenvolvida até certo ponto tem, graficamente falando, a

17 A reconstrução detalhada deste exemplo segundo estas linhas encontra-se em Balzer, Moulines e Sneed (1987), que é fundado sobre Balzer e Moulines (1982).

Perspectivas - Revista do Programa de Pós-Graduação em Filosofia da UFT - n.2 - 2018 
forma de uma 'pirâmide': no topo dela, encontramos axiomas muito gerais e seus tipos correspondentes de modelos; estes se tornam sucessivamente especializados em diferentes direções até que, em alguns pontos, alcançamos o nível de aplicações muito concretas.

É neste ponto, o mais tardar, que a ideia simplista de uma teoria científica como um conjunto de axiomas se desfaz completamente. Esta ideia é bastante inadequada para representar a estrutura complexa, fortemente hierárquica e multinível das teorias científicas. É uma tarefa importante para a filosofia contemporânea da ciência tornar explícitas as consequências epistemológicas e metodológicas gerais desta nova concepção de teorias.

\section{REFERÊNCIAS}

BALZER, W. \& C. U. MOULINES. Die Grundstruktur der klassischen Partikelmechanik und ihre Spezialisierungen. Zeitschrift für Naturforschung, v. 36, n. 6, p. 600-608, 1981.

BALZER, W.; MOULINES, C. U. \& J. D. SNEED. An Architectonic for Science. The Structuralist Program. Dordrecht: Reidel, 1987.

BALZER, W.; MOULINES, C. U. \& J. D. SNEED (eds.). Structuralist Knowledge Representations: Paradigmatic Examples. Amsterdam: Rodopi, 2000.

CARNAP, R. The Continuum of Inductive Methods. Chicago: The University of Chicago Press, 1952.

CARNAP, R. \& R. JEFFREY. Studies in Inductive Logic and Probability. Berkeley: University of California Press, 1971.

DÍEZ, J. A. A Hundred Years of Numbers. An Historical Introduction to Measurement Theory. Part I: The Formation Period. Studies in History and Philosophy of Science, v. 28, n. 1, p. 167-181, 1997a.

DÍEZ, J.A. A Hundred Years of Numbers. An Historical Introduction to Measurement Theory. Part I: Suppes and the Mature Theory. Studies in History and Philosophy of Science, v. 28, n. 2, p. 237-265, 1997 b.

DÍEZ, J. A. \& C. U. MOULINES. Fundamentos de filosofía de la ciência. Barcelona: Ariel, 1999.

DUHEM, P. La théorie physique, son objet, sa structure. Paris: Vrin, [1906] 1981.

HENKIN, L.; SUPPES, P. \& A. TARSKI (eds.). The Axiomatic Method. Amsterdam: North-Holland, 1959.

KRANTZ, D. et al. Foundations of Measurement. I. New York: Academic Press, 1971. 
KUHN, T.S. The Structure of Scientific Revolutions. Chicago: The University of Chicago Press, 1970.

KYBURG, H. E. Philosophy of Science. A Formal Approach. New York: Macmillan, 1968.

MOULINES, C. U. La philosophie des sciences. L'invention d'une discipline. Paris: Editions de la Rue d’Ulm, 2006.

MOULINES, C. U. \& J. A. DÍEZ. Theories as Nets: Combinatorial Measurement Theory. In HUMPHREYS, P. (ed.). Patrick Suppes, Mathematical Philosopher. Dordrecht: Kluwer, 1994, pp. 275-297.

NAGEL, E. The Structure of Science. New York: Harcourt, 1961.

POPPER, K. R. Logik der Forschung. Vienna: J. Springer, 1934. (Edição inglesa revisada e ampliada: The Logic of Scientific Discovery. London: Hutchinson, 1958.)

POPPER, K. R. Objective Knowledge. Oxford: Clarendon Press, 1972.

QUINE, W. V. O. From a Logical Point of View. New York: Harper and Rowe, 1953.

STEGMÜLLER, W. Theorie und Erfahrung. Berlin-Heidelberg: Springer, 1970.

STEGMÜLLER, W. Theorienstrukturen und Theoriendynamik. Berlin-Heidelberg: Springer, 1973.

STEGMÜLLER, W. Personelle und statistische Wahrscheinlichkeit. Berlin-Heidelberg: Springer, 1974.

SUPPE, F. The Semantic Conception of Theories and Scientific Realism. Chicago: University of Illinois Press, 1989.

SUPPES, P. Introduction to Logic. New York: Van Nostrand, 1957.

SUPPES, P. Models of Data. In NAGEL, E.; SUPPES, P. \& A. TARSKI (eds.). Logic, Methodology and Philosophy of Science. Proceedings of the 1960 International Congress. Stanford: Stanford University Press, 1962, pp. 252-261.

TARSKI, A. Logic, Semantics, Metamathematics, Papers from 1923 to 1938. Oxford: Clarendon Press, Oxford, 1956.

VAN FRAASSEN, B. The Scientific Image. Oxford: Clarendon Press, 1980. 